\title{
Resection of a Retrochiasmatic Craniopharyngioma by Combined Modified Orbital Craniotomy and Transnasal Endoscopic Techniques
}

\author{
Nirav J. Patel ${ }^{1} \quad$ Ian Dunn ${ }^{1}$ \\ ${ }^{1}$ Department of Neurosurgery, Brigham and Women's Hospital, \\ Harvard Medical School, Boston, Massachusetts, United States \\ J Neurol Surg B 2018;79(suppl S3):S243-S244.
}

\begin{abstract}
Address for correspondence Nirav J. Patel, MD, Department of Neurosurgery, Brigham and Women's Hospital, Harvard Medical School, 75 Francis Street, BTM4, \#4196, Boston, MA 02115, United States (e-mail: npatel40@bwh.harvard.edu).
\end{abstract}

Funding

None.

Conflict of Interest

None.
A 20-year-old patient presented with hydrocephalus but intact vision and hormone function. The MRI showed a large seller, suprasellar and third ventricular mass. We chose a combined approach utilizing the translyvian, lamina terminals route, with a possible interhemispheric approach. But, we also utilized a transnasal endoscopic approach for the tumor that remained below the diaphragma sellae. The patient did well, with complete tumor resection via a staged approach, but did require hormone replacement.

The link to the video can be found at: https://youtu.be/yzpfOxzl4cQ.

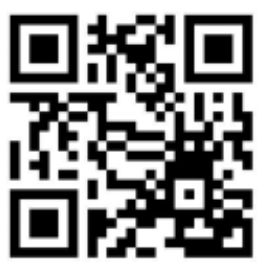

received

October 29, 2017

accepted

November 29, 2017

published online

February 28, 2018

www.thieme.com/skullbasevideos

www.thieme.com/jnlsbvideos

DOI https://doi.org/

10.1055/s-0038-1623519.

ISSN 2193-6331. (c) 2018 Georg Thieme Verlag KG

Stuttgart · New York
License terms

(ㄷ) (i) $\ominus$ (요 


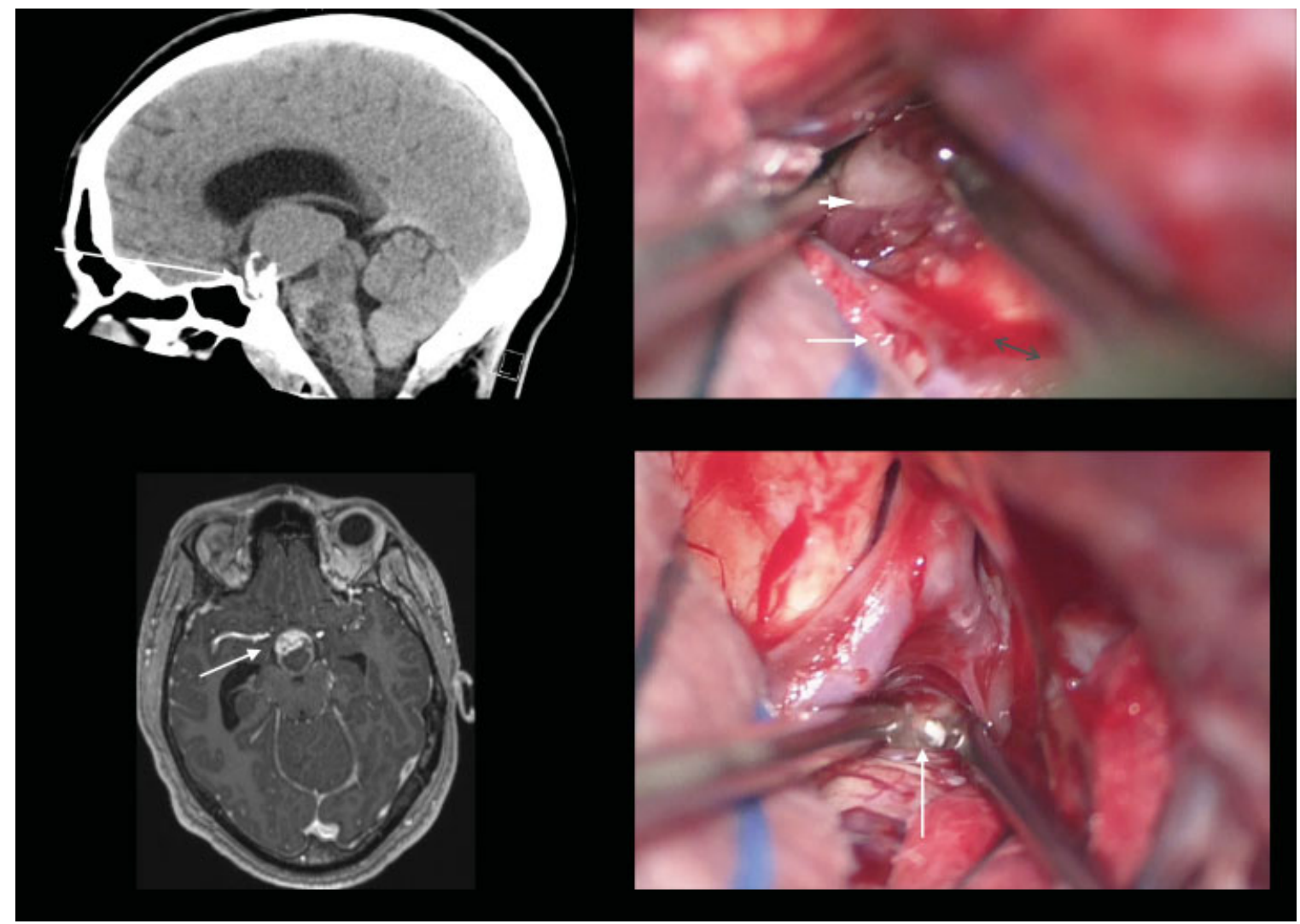

Fig. 1 (A) Through a right transylvian approach, the tumor is removed from the lamina terminals (arrowhead). The right A1 (white arrow) and chiasma (black arrow) are seen. The CT scan shows the approximate trajectory to access the third ventricular component. (B) The supraseller component is seen in the MRI (arrow) and removed between the ICA and PCOM (arrow). CT, computed tomography; ICA, internal carotid artery; MRI, magnetic resonance imaging; PCOM, posterior communicating artery. 